\title{
Challenges and opportunities in the implementation of electronic commerce: The case of Nigeria
}

\author{
Chris Adalikwu \\ College of Business, Hankuk University of Foreign Studies 270-Imundong, Dongdaemungu, Seoul-130-791, KOREA. \\ E-mail: akwa22000@yahoo.com.
}

Accepted 18 October, 2012

\begin{abstract}
This research paper examines the statistical significance of various problems in implementation of ecommerce solutions in business organizations in Nigeria. Nigeria has witnessed substantial progress in the field of ICT-related infrastructural development in the first decade of the $21^{\text {st }}$ century. However, despite these positive developments and abundant resources, Nigeria has not been able to catch up with the pace of digital development as the rest of the world. This research paper attempts to identify the problems in implementing e-commerce in Nigeria. On the basis of analysis of data through hierarchical multiple regression modeling and multiple response analysis of the data, this study identifies the statistically significant problems in the implementation of e-commerce in Nigeria and outlines the key policy options that this country, can consider in formulation of policies to stimulate, support and maximize the effect e-commerce has on their economies.
\end{abstract}

Key words: E-commerce, problems, Nigeria, hierarchical multiple regression.

\section{INTRODUCTION}

Rapid advancements in the field of information and telecommunications technologies in the first decade of $21^{\text {st }}$ century have been truly remarkable and have resulted in the amazing transformation of some societies (notably Western) into information-based cultures. The fast emergence and acceptance of e-commerce has resulted in a deep positive impact on business world. It is being implemented rapidly in business establishments in different sectors of the economy worldwide. Multi-national companies are early adopters of e-commerce. As these companies conduct business in multiple countries and work through numerous supply-chain components such as suppliers, original equipment manufacturers, dealers, importers and carry-and-forward ( $\mathrm{C}$ and $\mathrm{F}$ ) agents, distributors and retailers etc., the coordination between these entities has become vital so as to be successful in the competitive environment. An integrated supply chain with a well-designed e-commerce infrastructure has dramatically improved their performance and minimized costs.

The use and application of electronic commerce in business practices is quite varied between different parts of the world. There has been rapid growth in the use of e- commerce in North American, Western Europe, and South East Asian countries, while West Africa is yet to see that level of growth. Nigeria, which is the most populous and resource-rich country in Africa, provides an ideal context for the analysis of the problems in ecommerce development and implementation.

Nigeria, being one of the world's most promising and competitive economies, is one of the perfect investment destinations on the landscape of Africa. According to most global investment and economic reports, Nigeria is considered as a fast-emerging world economic center relative to business climate, a free and competitive marketing system, consumer and purchasing power parity, market reforms, oil and related resource-rich reserves and fiscal freedom.

\section{Research problem}

Despite all of the above positive indicators, electronic commerce is still in its early stages of implementation in Nigeria. Electronic commerce solutions adoption and implementation are far from adequate in the entire nation. 
The problems faced by business sectors in the implementation of e-commerce solutions are multi-faceted. This is further compounded by cultural constraints, digital illiteracy, a vastly absent enabling infrastructural environment, and the often limited awareness at decision-making levels of the importance of sound and forward-looking ICT policies and strategies as well as of the potential for ICT applications.

\section{Study objectives}

This paper aims to achieve two specific objectives:

1. to identify various problems faced by business establishments in implementing e-commerce solutions in Nigeria,

2. to examine the statistical significance of these problems.

\section{REVIEW OF LITERATURE}

A review of the available literature shows that there is a paucity of writings focusing on the problems in implementing e-commerce solutions in business organizations in Nigeria. In this part of the world, it is one of the most overlooked areas, where writings still focus on end-user computing and on developing models for SMEs rather than on analyzing what has happened during the implementation of e-commerce.

No existing literature on e-commerce was found to offer a holistic view of the problems with statistical significance affecting e-commerce implementation in Nigeria. Very negligible work has been done to examine the available literature that does throw some light on this issue.

Begin and Boisvert (2002) analyzed the strategic factors that influence e-commerce implementation in Canada. They did a micro-level study to identify these factors. In their study, the focus was on identifying the developments within each organization that influenced ecommerce implementation. They tried to classify the factors into groups that could serve as good starting points to analyze these factors and identify their influence on e-commerce implementation results; however, the biggest limitation of this study was that it did not take into account any of the external factor, and their study does not include any statistical analysis of the problems that affect the implementation of e-commerce.

Teo et al. (2004) have done a meta-analysis of literature related to factors affecting the adoption of ecommerce, specifically in small and medium enterprises. Existing literature shows that it was among the first few meta-analysis of the factors affecting the implementation of e-commerce. However, their study concentrated on identifying specific factors and in the process ignored the holistic view of the problem. They have identified some meta-factors from the available studies, which are related to adoption of e-commerce. However, different studies have conflicting viewpoints about these meta-factors. In addition, none of these meta-factors measure the impact of e-commerce implementation results, nor do they identify the major barriers in its implementation at the business level.

Studies undertaken by Radovilsky and Hegde (2004) and Zhu (2004) were good efforts in this direction; however, these studies were related to North America and emphasized the technological competence of the firm in the diffusion of e-commerce. They failed to identify the apparent and latent social, cultural other demographic obstacles in the implementation of e-commerce solutions.

A study undertaken by Oreku et al. (2011) helps in identifying the important factors in implementing electronic commerce; however, the study was carried out in East Africa, which has a somewhat different cultural environment as compared to West Africa where Nigeria is located. Most of the research in this field suggests that factors such as culture, economic condition, consumer behavior, purchasing power and parity have a direct bearing on the implementation of e-commerce. As there is a substantial difference between East Africa and West Africa on economic, social and cultural parameters, these findings may not be specifically applicable.

On the basis of overall evaluation of available literature sources, it is evident that there is clear need for a research undertaking designed to identify and analyze the factors that influence the implementation of $e$ commerce solutions in various organizations. In this study, efforts are being taken to address the specified issues of establishing and analyzing such factors.

\section{METHODOLOGY}

This study is centered on examining the different aspects of the electronic commerce implementation results. The objectives are to identify what major barriers and impediments exist in regard to using and implementing e-commerce solutions, and secondly to examine the statistically significant relationship between two variables; that is,the major obstacles in e-commerce implementation results. Hence, in the light of these two specifics within the quantitative paradigm, the methodology used is crosssectional descriptive research design.

\section{Sampling design}

The sample frame was obtained from a list representatives of the entire market in Nigeria. Respondents were screened by asking the question, "Do you use the Internet to buy, sell, or support products or services?" The final sample thus represents firms actually using the Internet for business, rather than representing the full population of Nigeria. The final sample size from Nigeria included 237 business establishments. Respondents were CIOs, CEOs, IS directors or IT managers; that is, the people actually involved in key decisions about e-commerce implementation and use.

A stratified random sampling technique from the probability sampling method has been used in this research. The sample was stratified by firm size, in accordance with the Organization for Economic Cooperation and Development (OECD) classification 
standards. Business establishments were distributed across three industry sectors that are considered as the leading users of the Internet and e-commerce. These were the trading sector (wholesale/retail distribution), the services sector and the manufacturing sector, and the only business establishments considered were those in which electronic commerce had been implemented.

From the strata based on company size, random numbers (The Rand Corporation, 1955) were allocated to each unit of the sampling frame and, using a simple random sampling technique, the final sample was selected from each stratum.

\section{Sample size, level of precision, confidence level and degree of variation}

For determining the sample size, a mathematical formula developed by Yamane (1967) was used. The original Yamane formula is as follows:

$\mathrm{n}=\mathrm{N} /\left[1+\mathrm{N}(\mathrm{e})^{\wedge} 2\right]$

Where: $\mathrm{n}=$ sample size, $\mathrm{N}=$ population size, $\mathrm{e}=$ the level of precision, $z=$ the value of the standard normal variable given the chosen confidence level (CL); e.g., $z=1.96$ with a $C L=95 \%$, and $z$ $=2.57$ with $\mathrm{a} \mathrm{CL}=99 \%, \mathrm{P}=$ the proportion or degree of variability

To understand the mathematical formula, we need to understand the major criteria for determining sample size. According to Miaoulis and Michener (1976) and others, three major criteria are usually taken into consideration for determining sample size. These three criteria are as follows:

1) level of precision (decided to keep it at $\pm 5 \%$ )

2) confidence level (kept at 95\%)

3) degree of variability in the attributes being measured (0.5).

Calculated through above mathematical formulation, the sample size for Nigeria was found to be 237 . The questions used in the questionnaire used both nominal well as ordinal scales. The final sample (sample size: 237) represents firms actually using the Internet for business rather than the full population of firms in each country.

\section{Survey instrument, its reliability and validity assessment}

The survey instrument was planned and designed on the basis of an extensive literature review and discussion with IT managers. The instrument used in this research was adapted from the original model instrument developed by Organization for Economic Cooperation and Development (OECD), the instruments designed by Kraemer et al. (2006) and Radovilsky and Hegde (2004), and discussions with the practicing IT managers after assessing the instrument's reliability and validity. The instrument designed by Kraemer et al. (2006) has been reviewed and critiqued by International Data Corporation's Global Research Organization and its global subsidiaries in the countries studied. The final instrument used for data collection was a structured, non-disguised questionnaire containing all close-ended questions with multiple choices.

In this research study, the internal consistency reliability of the instrument was measured by applying Cronbach's alpha. Using Cronbach's Alpha $(\alpha)$, the item-wise reliability coefficient was found to be in the range of 0.7186 to 0.9142 , hence it appears to be acceptable. From the test-retest method, the same results were obtained on the two successive administrations of the instrument, and the reliability coefficient was found to be in the range of 0.7018 to 0.9225 . Hence, the reliability of the instrument appeared to be acceptable.

The validity of the instrument was tested on content and constructs validity. Panel evaluations by 12 practicing managers (subject-matter experts) was done for assessing the content validity of the instrument. They were requested to assess each item of the instrument. For all the measurement items, ten (out of twelve) subject-matter experts rated the items as essential. The content validity ratio (CVR ) for all measurement items was found to be in the range of 0.667 to 0.833 . The mean CVR of items retained is the "content validity index" for the total test, and it is 0.756 . Mean Content Validity Index for total test $=0.756$

Since the mean CVR (which is 0.756 ) is positive and strong as it is closer to +1.0 , the items in the instrument appears to have an acceptable content validity. For assessing the construct validity of the research instrument, the exploratory factor analysis method was used. The result confirmed that the instrument exhibited satisfactory construct validity. The data was examined using principal components analysis as the extraction technique, and Varimax with Kaiser normalization as the method of rotation. From the factor analysis, it was found that all the items have factor loading in excess of 0.7 . Hence, the result confirms that the instrument has satisfactory construct validity.

\section{Data analysis procedure}

For identifying the problems in the implementation of e-commerce in Nigeria, a two-phased process has been used. In the first phase, SPSS 16.0 multiple response analysis techniques were used to identify the various obstacles. The multiple response analysis command allows users to analyze a number of separate variables at the same time and is best used in situations where the responses to a number of separate variables have a similar coding scheme that all 'point to' a single underlying variable. In this research, each of the items in the question appear to negatively affect e-commerce implementation. It helps to summarize the responses to these items all at once so that the pattern of responses across these items in further analysis with other variables can be used.

In the second phase, hierarchical multiple regression modeling (SPSS 16.0) has been used. It is an advanced variant of the basic multiple regression procedure that allows users to specify a fixed order of entry for variables in order to control for the effects of covariates or to test the effects of certain predictors independent of the influence of others. Hierarchical multiple regression modeling, a form of multi-level analysis, is a more advanced form of simple linear regression and multiple linear regression analysis that allows the variance in outcome variables to be analyzed at multiple hierarchical levels.

\section{RESULTS AND DISCUSSION}

Various major obstacles/problems in the implementation of e-commerce in Nigeria was identified through pilot survey. After the reliability and validity assessment of the instrument, a fully-fledged survey was undertaken. Thirteen major obstacles were listed, and the respondents were asked to evaluate these items according to their point of view. The question was the following: "Using a five-point scale, where five is 'a very significant factor' and one is 'not a factor at all,' please rate how much do the following obstacles affect your organization's ability to implement e-commerce solutions/ 
Table 1. Multiple response analysis (SPSS 16.0 multiple response crosstabs output).

\begin{tabular}{lccc}
\hline & \multicolumn{2}{c}{ Response } & Percent of \\
\cline { 2 - 3 } & Count & Percent & cases (\%) \\
\hline Lack of awareness of e-commerce & 120 & 7.0 & 50.6 \\
Limited knowledge of available technology & 44 & 2.6 & 18.6 \\
Lack of confidence in benefits of e-commerce & 65 & 3.9 & 27.8 \\
Shortage of skilled human resources & 171 & 10 & 72.2 \\
High cost of implementing e-commerce solution & 44 & 2.6 & 18.6 \\
Relatively small size of market for e-commerce & 185 & 10.9 & 78.1 \\
Lack of trust between customer and company & 154 & 9.0 & 65 \\
Lack of supporting business law for e-commerce & 206 & 12.1 & 86.9 \\
Insufficient infrastructure for e-commerce & 12 & 0.7 & 5.1 \\
Difficulty in integrating e-commerce with existing system & 192 & 11.3 & 81.0 \\
Resistance in adopting e-commerce & 101 & 5.9 & 42.6 \\
Concern for data security and privacy & 202 & 12.6 & 85.2 \\
Low return on investment & 101 & 5.9 & 42.6 \\
\hline
\end{tabular}

Table 2. SPSS output of rating of the problems (Major problems in implementing electronic commerce in Nigeria) using a 5-point scale.

\begin{tabular}{lccccc}
\hline & $\mathbf{1}$ & $\mathbf{2}$ & $\mathbf{3}$ & $\mathbf{4}$ & $\mathbf{5}$ \\
\hline Lack of awareness of e-commerce (\%) & 50 & 35 & 15 & 00 & 00 \\
Limited knowledge of available technology (\%) & 58 & 12 & 12 & 25 & 01 \\
Lack of confidence in benefits of e-commerce (\%) & 50 & 21 & 20 & 09 & 00 \\
Shortage of skilled human resources (\%) & 00 & 12 & 15 & 18 & 55 \\
Cost of initial investment in adopting e-commerce (\%) & 54 & 22 & 12 & 07 & 05 \\
Relatively small size of market for e-commerce (\%) & 00 & 10 & 10 & 32 & 48 \\
Lack of trust between customer and company (\%) & 00 & 11 & 20 & 25 & 44 \\
& & & & & \\
Lack of supporting business law for e-commerce (\%) & 00 & 04 & 08 & 51 & 37 \\
Insufficient infrastructure for e-commerce (\%) & 70 & 20 & 10 & 00 & 00 \\
Difficulty integrating e-commerce with existing system (\%) & 00 & 00 & 12 & 10 & 78 \\
Resistance in adopting e-commerce (\%) & 65 & 15 & 10 & 10 & 00 \\
Concern for data security and privacy (\%) & 00 & 05 & 07 & 20 & 68 \\
Low return on investment (\%) & 00 & 12 & 19 & 19 & 50 \\
\hline
\end{tabular}

Where 5 is "a very significant problem" and 1 is "not an obstacle at all."

do business online." Using the SPSS 16.0 multiple response command, all these separate variables (multiple responses to above question) were analyzed, and the important ones were identified. In the second part, hierarchical multiple regression modeling was used to further analyze the variables and test their statistical significance.

In the multiple response analysis, it has been observed that the following factors are the widely recognized problems/obstacles in implementing electronic commerce in Nigeria: "concern for data security and privacy," "difficulty in integrating e-commerce software with the existing system," "lack of supporting business law," "small size of market for e-commerce," and "lack of skilled manpower." Table 1 shows the details of the respondent's answers to aformentioned question. Although these five barriers were highlighted by the respondents in the survey, it is possible that their identification is only due to chance and that this data has no statistical significance. Hence, further statistical analysis is required to find out their statistical significance.

In order to further examine the statistical significance of these problems/obstacles in the implementation of $e$ commerce in Nigeria, hierarchical multiple regression modeling in SPSS has been used. It is a variant of the basic multiple regression procedure that allows the user to specify a fixed order of entry for variables in order to control for the effects of covariates or to test the effects of 
Table 3. Variable description.

\begin{tabular}{ll}
\hline Dependent variable & Variable indicator \\
\hline e-commerce implementation & ecom_implmnt \\
\hline Independent variable & Variable indicator \\
\hline Lack of awareness of e-commerce & lack_awareness_ecom \\
Limited knowledge of available technology & Imt_knowledge_tech \\
Lack of confidence in benefits of e-commerce & lack_confidence_ecom \\
Cost of initial investment in adopting e-commerce & highcost_imple_ecom \\
Lack of trust between customer and company & lack_trust_cust_company \\
Insufficient infrastructure for e-commerce & infrastructure_ecom \\
Resistance in adopting e-commerce & resistance_ecom_adption \\
Low return on investment & lowreturn_investment \\
Relatively small size of market for e-commerce & small_market_ecom \\
Lack of supporting business law for e-commerce & lack_busi_law_ecom \\
Concern for data security and privacy & concern_data_security \\
Difficulty in integrating e-commerce with existing system & difficulty_integrating \\
Shortage of skilled human resources & shortage_skilled_hr \\
\hline
\end{tabular}

certain predictors, independent of the influence of others. In this hierarchical regression analysis model, the variables have been named as shown in Table 3.

The hierarchical regression model contains thirteen categories of independent variables (obstacles) hereafter referred to as predictors. In this analysis, the five most important problems/obstacles (identified in the multiple response analysis - the last five variables shown in Table 3) were examined to find out whether they substantially contribute to obstacles in the implementation of $e$ commerce in Nigeria. At the same time, it is possible that other variables might be associated with obstacles in ecommerce implementation. To make sure that these variables do not explain away the entire association between the above-mentioned predictors and obstacles in e-commerce implementation, all other predictors (other than the five selected predictors) have been put into the first model (Table 4). This ensures that they will get "credit" for any shared variability they may have with the predictor that is the focus of this paper.

The following are the meaning of the model as indicated in Table 4.

1. Model 1 refers to the first stage in the hierarchy when the first set of predictors are included in the model.

2. Model 2 refers to the second stage in the hierarchy when the predictor "small size of market for e-commerce" is considered as contributing to obstacles in e-commerce implementation.

3. Model 3 refers to the third stage in the hierarchy when the set of predictors "small size of market for ecommerce" and "lack of supporting business law for ecommerce" are considered as contributing to obstacles in e-commerce implementation.

4. Model 4 refers to the fourth stage in the hierarchy when the set of predictors "small size of market for ecommerce," "lack of supporting business law for ecommerce" and "concern for cyber-crime, data security and privacy" are considered as contributing to obstacles in e-commerce implementation.

5 . Model 5 refers to the fifth stage in the hierarchy when the set of predictors "small size of market for ecommerce," "lack of supporting business law for ecommerce," "concern for cyber-crime, data security and privacy" and "shortage of skilled human resources" are considered as contributing to obstacles in e-commerce implementation.

6. Model 6 refers to the sixth stage in the hierarchy when the set of predictors "small size of market for ecommerce," "lack of supporting business law for ecommerce," "concern for cyber-crime, data security and privacy," "shortage of skilled human resources" and "difficulty in integrating e-commerce software with existing system" are considered as contributing to obstacles in e-commerce implementation.

The SPSS output in the form of the Model Summary (Table 4) shows that the percent of "variability in the dependent variable that can be accounted for" by all the predictors together (that's the interpretation of R-square). In the column labeled $R$ are the values of the multiple correlation coefficients between the predictors and the outcome. The next column gives a value of $\mathrm{R}^{2}$, which is a measure of how much of the variability in the outcome is accounted for by the predictors.

The change in $R^{2}$ is a way to evaluate how much predictive power was added to the model by the addition of another variable in step 2. In this case, the percentage of "variability in the outcome accounted for", went up from 4.7 to $26 \%$ - a substantial increase of more than $21 \%$. The "Durbin-Watson" statistic informs about whether the 
Table 4. Model summary

\begin{tabular}{ccccccccccc}
\hline \multirow{2}{*}{ Model } & \multirow{2}{*}{$\mathbf{R}$} & \multirow{2}{*}{$\mathbf{R}^{\mathbf{2}}$} & \multirow{2}{*}{ Adj. $\mathbf{R}^{\mathbf{2}}$} & \multirow{2}{*}{ Std. error of est. } & \multicolumn{5}{c}{ Change statistics } & Durbin- \\
\cline { 6 - 9 } & & & & $\mathbf{R}^{2}$ change & F-change & DF1 & DF2 & Sig. F-change & Watson \\
\hline 1 & $.144^{\mathrm{a}}$ & .021 & .032 & .40254 & .125 & 4.081 & 8 & 228 & .000 & \\
2 & $.355^{\mathrm{b}}$ & .126 & .091 & .40327 & .001 & .175 & 1 & 227 & .676 \\
3 & $.403^{\mathrm{c}}$ & .163 & .126 & .39560 & .037 & 9.889 & 1 & 226 & .002 & \\
4 & $.414^{\mathrm{d}}$ & .171 & .131 & .39440 & .009 & 2.382 & 1 & 225 & .124 & \\
5 & $.415^{\mathrm{e}}$ & .172 & .128 & .39510 & .001 & .200 & 1 & 224 & .655 & \\
6 & $.422^{\mathrm{f}}$ & .178 & .130 & .39451 & .006 & 1.672 & 1 & 223 & .197 & 1.674 \\
\hline
\end{tabular}

${ }^{a}$ Predictors: Constant, lowreturn_investment, Imt_knowledge_tech, infrastructure_ecom, lack_confidence_ecom, lack_awareness_ecom, resistance_ecom_adption, lack_trust_cust_company, highcost_imple_ecom.

${ }^{b}$ Predictors: Constant, lowreturn_investment, Imt_knowledge_tech, infrastructure_ecom, lack_confidence_ecom, lack_awareness_ecom, resistance_ecom_adption, lack_trust_cust_company, highcost_imple_ecom, small_market_ecom.

${ }^{\mathrm{c}}$ Predictors: Constant, lowreturn_investment, Imt_knowledge_tech, infrastructure_ecom, lack_confidence_ecom, lack_awareness_ecom, resistance_ecom_adption, lack_trust_cust_company, highcost_imple_ecom, small_market_ecom, lack_busi_law_ecom.

${ }^{d}$ Predictors: Constant, lowreturn_investment, Imt_knowledge_tech, infrastructure_ecom, lack_confidence_ecom, lack_awareness_ecom, resistance_ecom_adption, lack_trust_cust_company, highcost_imple_ecom, small_market_ecom, lack_busi_law_ecom, concern_data_security.

${ }^{e}$ Predictors: Constant, lowreturn_investment, Imt_knowledge_tech, infrastructure_ecom, lack_confidence_ecom, lack_awareness_ecom, resistance_ecom_adption, lack_trust_cust_company, highcost_imple_ecom, small_market_ecom, lack_busi_law_ecom, concern_data_security, shortage_skilled_hr.

${ }^{\mathfrak{f}}$ Predictors: Constant, lowreturn_investment, Imt_knowledge_tech, infrastructure_ecom, lack_confidence_ecom, lack_awareness_ecom, resistance_ecom_adption, lack_trust_cust_company, highcost_imple_ecom, small_market_ecom, lack_busi_law_ecom, concern_data_security, shortage_skilled_hr, difficulty_integrating.

assumption of independent errors is tenable. The closer to that the value is, the better, and for these data the value is 2.431, which is somewhat close to the value of adjusted $\mathrm{R}$ square; hence, it can stated that the assumption has almost certainly been met.

The analysis of variance (ANOVA) as shown in Table 5 reinforces our earlier findings as it tests the acceptability of the model from a statistical perspective. Here, all the models predicted scores on the dependent variable to a statistically significant degree, as the significance values of all the models is less than 0.05 . Here, it is important to note that the value of $F$ defines the accuracy of the regression model. If the value of $F$ is greater than 1 then it can be interpreted that the regression model overcomes the inaccuracy within the model and that the SPSS calculates the exact probability of obtaining the value of $\mathrm{F}$ by chance. For the initial model, the F-ratio is 4.081, having the p-value of 0.070 . Therefore, it is not statistically significant. For the second model, the F-ratio is 3.634, and it is highly unlikely to have happened by chance (as its p-value is less than 0.05). For the third model, the value of $F$ is 4.388 , which is also highly significant $(p<0.05)$. The value of F-ratio of fourth, fifth and sixth models are 4.230, 3.880 and 3.721, respectively, and all of them are also highly statistically significant $(p<0.05)$.

From these results, it may be safely interpreted that the final model might count as significant to predict the outcome variable.

The next part of the SPSS 16.0 output (Table 6) is concerned with the parameters of the model. Here, it is more important to look at the final model because it includes all predictors that make a significant contribution to predicting the relationship between predictors and inefficient e-commerce in Nigeria. In SPSS 16.0 output, the notation "Beta" is used to refer to standardized coefficients, while notation "B" is used to refer to unstandardized coefficients. The standardized regression coefficients represent the change in terms of standard deviations in the dependent variable (that is, implementation of e-commerce in Nigeria) that result from a change of one standard deviation in an independent variable mentioned in hierarchy of models.

The $B$ values tell us about the relationship between coefficient and each predictor. If the value is positive, it can be deduced that a positive relationship exist between the predictor and the outcome, whereas a negative coefficient represents a negative relationship. Each of these beta values has an associated standard error indicating to what extent these values would vary across different samples. Therefore, if the t-test associated with a $B$ value is significant and if the value in the column labeled significiant is less than 0.05 then that predictor is making a significant contribution to the model.

Here it clear from the output that for the final model (Table 6), a lack of supporting business law (lack_busi_law_ecom, $t=2.487, p<0.05$ ), concern for data security and privacy (concern_data_security, $t$ $=1.794, p<0.05)$ and difficulty in integrating e-commerce software with an existing system (difficulty_integrating, $t$ $=1.293, p<0.05)$ are statistically significant in terms of contribution to obstacles in e-commerce implementation as their p-value is lower than 0.05 while "shortage of skilled human resources" and "small size of market for ecommerce" are not statistically significant, as their significance value is higher than 0.05 . Since the 
Table 5. ANOVA.

\begin{tabular}{|c|c|c|c|c|c|}
\hline Model & Sum of squares & DF & Mean square & $\mathbf{F}$ & Sig. \\
\hline \multirow{3}{*}{1} & 5.291 & 8 & .661 & 4.081 & $.070^{\mathrm{a}}$ \\
\hline & 36.945 & 228 & .162 & & \\
\hline & 42.236 & 236 & & & \\
\hline \multirow{3}{*}{2} & 5.319 & 9 & .591 & 3.634 & $.000^{\mathrm{b}}$ \\
\hline & 36.917 & 227 & .163 & & \\
\hline & 42.236 & 236 & & & \\
\hline \multirow{3}{*}{3} & 6.867 & 10 & .687 & 4.388 & $.000^{\circ}$ \\
\hline & 35.369 & 226 & .157 & & \\
\hline & 42.236 & 236 & & & \\
\hline \multirow{3}{*}{4} & 7.237 & 11 & .658 & 4.230 & $.000^{\mathrm{d}}$ \\
\hline & 34.999 & 225 & .156 & & \\
\hline & 42.236 & 236 & & & \\
\hline \multirow{3}{*}{5} & 7.269 & 12 & .606 & 3.880 & $.000^{\mathrm{e}}$ \\
\hline & 34.968 & 224 & .156 & & \\
\hline & 42.236 & 236 & & & \\
\hline \multirow{3}{*}{6} & 7.529 & 13 & .579 & 3.721 & $.000^{\dagger}$ \\
\hline & 34.707 & 223 & .156 & & \\
\hline & 42.236 & 236 & & & \\
\hline
\end{tabular}

aPredictors: Constant, lowreturn_investment, Imt_knowledge_tech, infrastructure_ecom, lack_confidence_ecom, lack_awareness_ecom, resistance_ecom_adption, lack_trust_cust_company, highcost_imple_ecom.

${ }^{b}$ Predictors: Constant, lowreturn_investment, Imt_knowledge_tech, infrastructure_ecom, lack_confidence_ecom, lack_awareness_ecom, resistance_ecom_adption, lack_trust_cust_company, highcost_imple_ecom, small_market_ecom.

'Predictors: Constant, lowreturn_investment, Imt knowledge_tech, infrastructure_ecom, lack_confidence_ecom, lack_awareness_ecom, resistance_ecom_adption, lack trust cust company, highcost imple ecom, small market ecom, lack busi law ecom.

${ }^{d}$ Predictors: Constant, lowreturn_investment, Imt_knowledge_tech, infrastructure_ecom, lack confidence ecom, lack awareness ecom, resistance ecom adption, lack_trust_cust_company, highcost_imple_ecom, small_market_ecom, lack_busi_law_ecom, concern_data_security.

${ }^{e}$ Predictors: Constant, lowreturn_investment, Imt_knowledge_tech, infrastructure_ecom, lack_confidence ecom, lack awareness_ecom, resistance ecom adption, lack_trust_cust_company, highcost_imple_ecom, small_market_ecom, lack_busi_law_ecom, concern_data_security, shortage_skilled_hr.

fPredictors: Constant, lowreturn_investment, Imt_knowledge_tech, infrastructure_ecom, lack_confidence_ecom, lack_awareness_ecom, resistance_ecom_adption, lack_trust_cust_company, highcost_imple_ecom, small_market_ecom, lack_busi_law_ecom, concern_data_security, shortage_skilled_hr, difficulty_integrating.

standardized beta values $(\beta)$ are measured in standard deviation units, they are directly comparable. In this model, out of the five predictors, "lack of supporting business law for e-commerce," "concern for cyber crime, data security and privacy," and "difficulty in integrating ecommerce software with existing system" all have positive standardized beta values, which proves that they affect the implementation of e-commerce, while both "shortage of skilled human resources" and "small size of market for e-commerce" all have negative standardized beta values and hence may be considered as statistically non-significant in contributing to obstacles in e-commerce implementation.

\section{Conclusion}

From the multiple response analysis and hierarchical regression modeling of data obtained through surveys, it has been found that the major problem in implementing e-commerce is as a result of the following obstacles:

1. Lack of supporting business law for e-commerce.

2. Concern for cyber-crime, data security and privacy. 
Table 6. Coefficients for the sixth (final) model.

\begin{tabular}{lccccc}
\hline \multirow{2}{*}{ 6th model } & \multicolumn{2}{c}{ Unstandardized coefficient } & Standardized coefficient & \multirow{2}{*}{ t } & \multirow{2}{*}{ Sig. } \\
\cline { 2 - 4 } & $\mathbf{B}$ & Std. error & Beta & & \\
\cline { 2 - 4 } Constant & 1.512 & .558 & & .708 & .007 \\
lack_awareness_ecom & .184 & .065 & .018 & 2.829 & .085 \\
Imt_knowledge_tech & -.053 & .086 & -.049 & -.612 & .541 \\
lack_confidence_ecom & .029 & .078 & .031 & .378 & .706 \\
highcost_imple_ecom & -.206 & .118 & -.190 & -1.753 & .081 \\
lack_trust_cust_company & .011 & .090 & .013 & .125 & .900 \\
infrastructure_ecom & .003 & .130 & .001 & .021 & .983 \\
resistance_ecom_adption & .038 & .074 & .044 & .505 & .614 \\
lowreturn_investment & .038 & .107 & .040 & .356 & .722 \\
small_market_ecom & .271 & .085 & .531 & -.199 & .302 \\
lack_busi_law_ecom & .260 & .105 & .529 & 2.487 & .014 \\
concern_data_security & .161 & .090 & .158 & 1.794 & .024 \\
shortage_skilled_hr & .028 & .076 & .350 & -.365 & .125 \\
difficulty_integrating & .043 & .033 & .388 & 1.293 & .027 \\
\hline
\end{tabular}

3. Difficulty in integrating e-commerce with an existing system.

Based on the value of $R^{2}$, which is a measure of how much of the variability in the outcome is accounted for by the predictors, and by the Durbin-Watson statistic value is 2.431 , and which is somewhat closer to the value of adjusted $\mathrm{R}$ square, it can be stated that the assumption has almost certainly been met. As a rule of thumb, Durbin Watson test statistics value in the range of "more than 1" to "less than 3" is acceptable. Hence, the obtained value of Durbin-Watson statistic (which is 2.431) is well within the acceptable range.

From the analysis output, it is clear that out of the five predictors, "lack of supporting business law for ecommerce," "concern for cyber-crime, data security and privacy," and "difficulty in integrating e-commerce software with existing system" have positive standardized beta values, which prove that they affect the implementation of e-commerce in Nigeria. In the survey, it has been found that a lack of supporting business law for adopting and implementing e-commerce has also been cited as another major obstacle in Nigeria. In Nigeria, more than $80 \%$ of the business establishments surveyed face the obstacle of absence of supporting business laws in implementation of e-commerce. It assumes greater significance because of the fact that cyber-crimes are picking up pretty fast in this part of the world.

Hence, it can be safely concluded that the aforementioned three predictors are statistically significant and are major contributors in obstacles for e-commerce implementation in Nigeria.

\section{IMPLICATION FOR FUTURE RESEARCH}

The major focus of this study is the statistical analysis of problems in e-commerce implementation at the macrolevel. Since this study is more horizontal in terms of topical dimension, it will be highly appropriate if in future, an in-depth study is carried out to do more precise microlevel analysis on a case-to-case basis. Another important area in which future research is needed is to find out whether some of the problems identified here have any significant relation with the other parameters viz. size of the firm or the business nature of the firm. A substantial research effort is needed to examine the differences in problems in implementation of e-commerce by start-up firms and large multinational firms.

\section{Implication for managers}

As three major problems have been identified and found to be statistically significant in the implementation of $e$ commerce in Nigeria, managers should view these problems as significant to their responsibilities. The problem "difficulty in integrating e-commerce software with existing system" can best be handled at the organizational level, as the solution to this problem can be initiated within the organization with relevant outside technical assistance.

Another problem, "concern for cyber-crime, data security and privacy" can only be handled and solved by strengthening the cyber frontier of the firm, namely through the ever-evolving and off-the-shelf, readily available technological tools and techniques that can be 
customized accordingly.

\section{ACKNOWLEDGEMENT}

This research was supported by Hankuk University of Foreign Studies.

\section{REFERENCES}

Begin L, Boisvert H (2002). The Internal Factors that Can Make or Break E-commerce Implementation. (Special Focus on E-business Strategies). CMA Management, April, 22-25.

Kraemer KL, Melville NP, Zhu K, Dedrick J (2006). Global Ecommerce: Impacts of National Environment and Policy. Cambridge, New York, Cambridge University Press pp.389-402.

Miaoulis G, Michener RD (1976). An Introduction to Sampling. Dubuque, lowa: Kendall/Hunt Publishing Company.
Oreku GS, Mtenzi FJ, Ali AD (2011). The Prospects and Barriers of Ecommerce Implementation in Tanzania. Paper presented at ICIT 5th International Conference on Information Technology, Amman, Jordan, 11-13 May.

Radovilsky Z, Hegde VG (2004). Factors influencing e-commerce implementation: Analysis of survey results. J. Acad. Bus. Econ. 4(1):29-37.

SPSS 16.0 Command Syntax Reference 2008, SPSS Inc., Chicago III.

Teo TL, Chan C, Parker C (2004). Factors Affecting E-commerce Adoption by SMEs: A Meta- Analysis. ACIS 2004 Proceedings p.54.

The Rand Corporation (1955). A Million Random Digits with 100,000 Normal Deviates. Glencoe, IL: Free Press p.225.

Yamane $T$ (1967). Statistics, An Introductory Analysis $\left(2^{\text {nd }} E d\right)$. New York: Harper and Row p.58.

Zhu K (2004). E-commerce Capability: A Resource-Based Assessment of Their Business Value. J. Manag. Infor. Syst. 21(1):167-202. 